\title{
Pathological Complete Response and Successful Conversion Surgery After Nivolumab Therapy for Stage IV Oesophagogastric Junction Cancer
}

\author{
TSUTOMU KUMAMOTO ${ }^{1}$, TOSHIHIKO TOMITA ${ }^{2}$, YUDAI HOJO ${ }^{1}$, \\ TATSURO NAKAMURA ${ }^{1}$, YASUNORI KURAHASHI ${ }^{1}$, YOSHINORI ISHIDA ${ }^{1}$, \\ HIROTO MIWA ${ }^{2}$, SEIICHI HIROTA ${ }^{3}$ and HISASHI SHINOHARA ${ }^{1}$ \\ ${ }^{l}$ Department of Gastroenterological Surgery, Hyogo College of Medicine, Hyogo, Japan; \\ ${ }^{2}$ Division of Gastroenterology and Hepatology, Department of Internal Medicine, \\ Hyogo College of Medicine, Hyogo, Japan; \\ ${ }^{3}$ Department of Surgical Pathology, Hyogo College of Medicine, Hyogo, Japan
}

\begin{abstract}
Background: Multimodality treatment including immune check point inhibitors is required for stage IV oesophagogastric junction cancer (OGJC). Case Report: A 69year-old man, was diagnosed with advanced OGJC and paraaortic lymph node metastasis (T3N+M1, stage IV), which upon biopsy, was shown to be an adenocarcinoma. After eight courses of nivolumab as third-line chemotherapy, the primary tumour and enlarged regional and para-aortic lymph nodes shrunk markedly, while tumour markers decreased within normal ranges. We performed a minimally invasive Ivor-Lewis oesophagectomy with completion of an abdominal D2 and transhiatal lower mediastinal lymph node dissection. Pathological findings revealed a complete response for the primary tumour and a regional lymph node metastasis. A biopsy of the previous sample revealed microsatellite instabilitynegativity, Epstein-Barr virus-negativity, and programmed cell death-1-ligand combined positive score of 2. He was followed up for 3 months without recurrence. Conclusion: Nivolumab may induce pathological complete response for stage IV OGJC even in cases negative for microsatellite instability and EpsteinBarr virus, besides the programmed cell death-1-ligand combined positive score of $<5$.
\end{abstract}

This article is freely accessible online.

Correspondence to: Hisashi Shinohara (ORCID: 0000-0001-89311902), MD, PhD, Department of Gastroenterological Surgery, Hyogo College of Medicine, 1-1 Mukogawa-cho, Nishinomiya, Hyogo 663-8501, Japan. Tel: +81 798456767, Fax: +81 798456764, e-mail: shinohara@hyo-med.ac.jp

Key Words: Conversion surgery, Epstein-Barr virus, microsatellite instability, nivolumab, oesophagogastric junction cancer, programmed cell death-1-ligand.
The prognosis of patients with stage IV gastric cancer (GC) or oesophagogastric junction cancer (OGJC) remains poor, with a median survival time of 12.5 months (1). Recent studies have reported some success regarding conversion surgery for stage IV disease, largely because of the development of neoadjuvant chemotherapy (2, 3). Moreover, immune check point inhibitors have recently been approved for the management of advanced GC/OGJC as a palliative care treatment. A phase III trial, ATTRACTION-2, indicated that nivolumab had better survival benefits than placebo in the management of advanced GC/OGJC (4). Another phase II trial, KEYNOTE-158, showed the clinical benefit of pembrolizumab in the management of unresectable metastatic high microsatellite instability (MSI-H) noncolorectal cancer (5). Recently, the CheckMate649 phase III trial reported that nivolumab plus chemotherapy was a potential standard first-line treatment for metastatic GC or OGJC that expresses programmed cell death-1-ligand (PDL1), and it was recently granted FDA approval in the United States (6). Currently, three cases of advanced GC treated with conversion surgery after nivolumab treatment have been reported (7-9). However, there is limited information regarding the use, safety, and associated oncological outcomes of conversion surgery after nivolumab treatment for advanced GC. Furthermore, biomarkers predicting the effect of immunotherapy are still being investigated, although the involvement of MSI, Epstein-Barr virus (EBV), and PD-L1 combined positive score (CPS) has been reported $(6,10)$.

We report a case of MSI- and EBV-negative and PD-L1 CPS $<5$ stage IV OGJC successfully treated with conversion surgery after nivolumab treatment, which led to a pathological complete response (CR). 

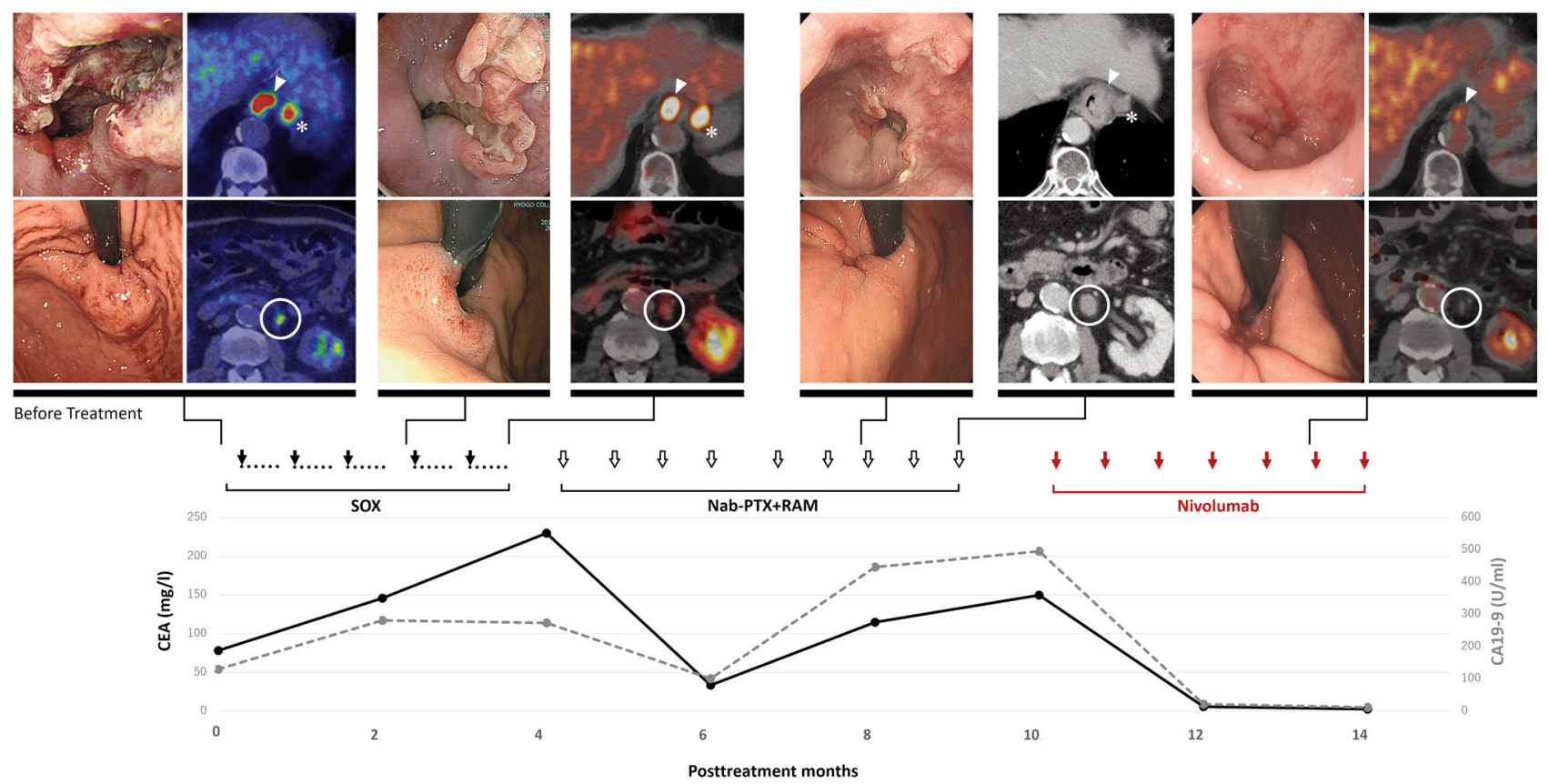

Figure 1. The course of preoperative assessment is shown, including findings of the tumour marker tests, oesophagogastroduodenoscopy, computed tomography, and positron emission tomography. Arrow heads indicate the primary tumour. Asterisks show the enlarged regional lymph node, and the para-aortic lymph node (station No. 16b1) is circled.

\section{Case Report}

A 69-year-old man complained of a sensation of something stuck in his throat and was diagnosed with advanced OGJC at a nearby hospital. He had a medical history of hypertension and hepatitis B. The patient's ECOG performance status was 0 , and his serum carcinoembryonic antigen (CEA) and carbohydrate (CA) $19-9$ levels were $78.3 \mathrm{mg} / \mathrm{ml}$ and 129.3 $\mathrm{U} / \mathrm{ml}$, respectively. Oesophagogastroduodenoscopy revealed a Siewert type II tumour that was classified as a human epidermal growth factor receptor 2(Her2)-negative poorly differentiated adenocarcinoma. Positron emission tomographycomputed tomography (PET-CT) revealed the primary tumour and metastasis to some regional lymph nodes (LNs) and paraaortic LNs (station Nos. 16a2 and 16b1).

The patient received entecavir hydrate for hepatitis B virus, and a SOX regimen, consisting of S-1 plus oxaliplatin, was initiated as first-line chemotherapy. After three courses of SOX, the patient was transferred from a nearby hospital to our institution. After five courses of SOX, CT and PETCT showed no remarkable changes of the regional and enlarged para-aortic LNs; however, the tumour markers were elevated. After five courses of nab-paclitaxel (PTX) and ramucirumab (RAM) therapy, the tumour markers were again elevated, and para-aortic LNs appeared larger on CT. Thus, third-line chemotherapy was initiated, which consisted of $240 \mathrm{mg} /$ body nivolumab administered every 2 weeks.
After eight courses of treatment, CEA and CA19-9 were within the normal ranges, and $\mathrm{CT}$ revealed that the enlarged regional and para-aortic LNs had markedly shrunk. Furthermore, PET-CT revealed no increases in the fluorine18 fluorodeoxyglucose (18F-FDG) uptake level. However, PET-CT revealed a slightly increased uptake in the oesophagogastric junctional area. The patient's course of treatment is summarised in Figure 1.

Staging laparotomy showed no peritoneal dissemination and negative peritoneal cytology. Therefore, we performed minimally invasive Ivor-Lewis oesophagectomy with abdominal D2 and transhiatal LN dissection (Figure 2A). The resected specimen had a macroscopically visible ulcerated scar at the site of the primary tumour (Figure 2B). There was no residual tumour, and a diagnosis of histological $\mathrm{CR}$ was made. One LN metastasis in station No. 1 was observed, but fibrous tissues were detected histologically in other LNs. The previous biopsy findings were confirmed, as immunostaining revealed Her-2 and EBV negativity (Figure 2C), and an MSI test (FALCO Biosystems, Kyoto, Japan) revealed MSI negativity. PD-L1 was not expressed by the tumour cells, but the CPS was 2 (Figure 2D). The patient's respiratory failure improved, and he was weaned from respiratory-assisted ventilation on postoperative day (POD) 8. The patient had aspiration pneumonia caused by silent aspiration on POD 22. Finally, the patient was discharged on POD 37. The patient had no recurrence at the 3-month follow-up. 


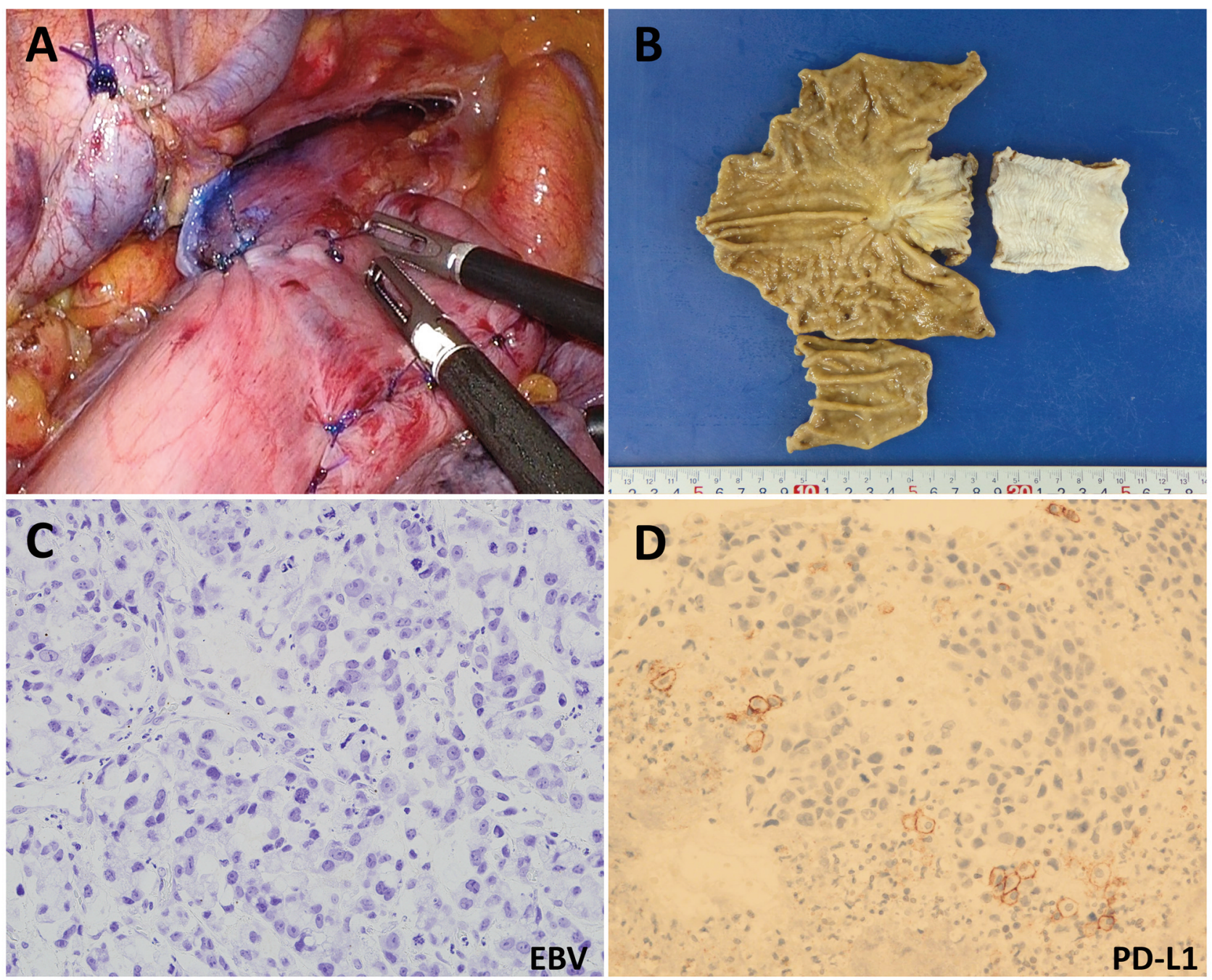

Figure 2. Operative and pathological findings. A) Operative findings after intrapleural oesophagogastric anastomosis using the overlap technique are shown. B) Macroscopic findings of the resected specimen show an ulcer in the primary tumour site. C) Epstein-Barr virus (EBV)-encoded RNA in-situ hybridisation shows that the tumour was EBV negative. D) Immune cell staining for the CC23 assay indicates that the programmed cell death-1-ligand combined positive score (PD-L1 CPS) was 2, while PD-L1 was not expressed by the tumour cells.

\section{Discussion}

The prognosis of stage IV GC/OGJC remains poor despite advances in chemotherapy (1). Some successful experiences have been reported regarding the use of conversion surgery for stage IV GC due to recent developments in chemotherapy $(2,3)$. Immune check point inhibitors are gradually beginning to occupy an important position after they were recently introduced for the treatment of GC/OGJC. However, there are still many unclear points, including the biomarkers predicting the effect of immunotherapy for advanced GC/OGJC.

The present case has two important features. First, a pathological CR was achieved for an MSI-negative, EBVnegative, and PD-L1 CPS $<5$ stage IV OGJC. Second, Ivor-
Lewis oesophagectomy, which is a major surgery in the field of gastrointestinal surgery, was performed safely. Regarding the pathological response, findings of the ATTARCTION-2 trial revealed a CR rate of $1.1 \%$ and an objective response rate of $11.9 \%$ after using nivolumab (11). It has been suggested that the existence of MSI and EBV may be used as biomarkers for predicting the effect of immunotherapy (10). Additionally, the recent global phase III (CheckMate 649) trial has reported at ESMO2020 and showed statistically significant improvements in overall survival and progression-free survival with nivolumab and fluoropyrimidine- and platinum-containing chemotherapy in a subset of patients with tumours that expressed PD-L1 with a CPS $\geq 5$, compared with those treated with chemotherapy alone (6). The tumour in this case was MSI- and EBV-negative, 
and the PD-L1 CPS was 2; furthermore, our patient experienced no major adverse events throughout the period. He received nivolumab and acquired an excellent pathological response. The result may be related to tumour mutational burden, which is currently attracting attention as another biomarker (12).

Only three recent cases of conversion gastrectomy in patients with stage IV GC after nivolumab therapy have been reported (7-9). The authors of a prior case report concluded that extended surgery should be carefully considered because pancreatic fistula and anastomotic leakage occurred in their patient (8). Another case study reported that modified LN dissection (D1+) was performed instead of the standard LN dissection (D2) using an open approach (9). A previous study also reported the occurrence of grade IIIa postoperative complications in $11 \%$ of patients who underwent conversion gastrectomy using chemotherapy (13). Therefore, the effects of the surgical procedure, including the approach and extent of LN dissection for conversion surgery, on postoperative complications should be considered. In our case, minimally invasive Ivor-Lewis oesophagectomy with lower mediastinal and abdominal D2 LN dissection was selected. LNs around the para-aortic and recurrent laryngeal nerves (station No. 106) were not dissected based on the final clinical diagnosis (ycTXNOM0); therefore, surgery-related complications were not observed postoperatively.

In conclusion, we reported the successful performance of a conversion surgery for a patient with MSI-negative, EBVnegative, and PD-L1 CPS $<5$ stage IV OGJC after the use of nivolumab. Currently, the long-term outcomes of the treatment remain unknown; however, our experience will be useful in determining the optimal treatment for patients with stage IV GC/OGJC as the effectiveness of immunotherapy after chemotherapy was found to be ineffective.

\section{Conflicts of Interest}

None of the Authors have any conflicts of interest to declare in relation to this study.

\section{Authors' Contributions}

TK and HS searched the literature, wrote the manuscript and created the figures. TT, YH, TN, YK, YI, HM, and SH searched literature and reviewed the manuscript.

\section{Acknowledgements}

This work was supported in part by JSPS KAKENHI (Grant Number: 19H03735).

\section{References}

1 Koizumi W, Kim YH, Fujii M, Kim HK, Imamura H, Lee KH, Hara T, Chung HC, Satoh T, Cho JY, Hosaka H, Tsuji A, Takagane A, Inokuchi M, Tanabe K, Okuno T, Ogura M,
Yoshida K, Takeuchi M, Nakajima T and JACCRO and KCSG Study Group: Addition of docetaxel to S-1 without platinum prolongs survival of patients with advanced gastric cancer: a randomized study (START). J Cancer Res Clin Oncol 140(2): 319-328, 2014. PMID: 24366758. DOI: 10.1007/s00432-0131563-5

2 Yamaguchi K, Yoshida K, Tanahashi T, Takahashi T, Matsuhashi $\mathrm{N}$, Tanaka Y, Tanabe $\mathrm{K}$ and Ohdan $\mathrm{H}$ : The long-term survival of stage IV gastric cancer patients with conversion therapy. Gastric Cancer 21(2): 315-323, 2018. PMID: 28616743. DOI: $10.1007 / \mathrm{s} 10120-017-0738-1$

3 Morgagni P, Solaini L, Framarini M, Vittimberga G, Gardini A, Tringali D, Valgiusti M, Monti M and Ercolani G: Conversion surgery for gastric cancer: A cohort study from a western center. Int J Surg 53: 360-365, 2018. PMID: 29654967. DOI: 10.1016/j.ijsu.2018.04.016

4 Kang YK, Boku N, Satoh T, Ryu MH, Chao Y, Kato K, Chung HC, Chen JS, Muro K, Kang WK, Yeh KH, Yoshikawa T, Oh SC, Bai LY, Tamura T, Lee KW, Hamamoto Y, Kim JG, Chin K, Oh DY, Minashi K, Cho JY, Tsuda M and Chen LT: Nivolumab in patients with advanced gastric or gastro-oesophageal junction cancer refractory to, or intolerant of, at least two previous chemotherapy regimens (ONO-4538-12, ATTRACTION-2): a randomised, double-blind, placebo-controlled, phase 3 trial. Lancet 390(10111): 2461-2471, 2017. PMID: 28993052. DOI: 10.1016/S0140-6736(17)31827-5

5 Marabelle A, Le DT, Ascierto PA, Di Giacomo AM, De JesusAcosta A, Delord JP, Geva R, Gottfried M, Penel N, Hansen AR, Piha-Paul SA, Doi T, Gao B, Chung HC, Lopez-Martin J, Bang YJ, Frommer RS, Shah M, Ghori R, Joe AK, Pruitt SK and Diaz LA Jr: Efficacy of pembrolizumab in patients with noncolorectal high microsatellite instability/mismatch repair-deficient cancer: results from the phase II KEYNOTE-158 study. J Clin Oncol 38(1): 1-10, 2020. PMID: 31682550. DOI: 10.1200/JCO.19.02105

6 Moehler M, Shitara K, Garrido M, Salman P, Shen L, Wyrwicz L, Yamaguchi K, Skoczylas T, Campos bragagnoli A, Liu T, Schenker M, Yanez P, Tehfe M, Poulart V, Cullen D, Lei M, Kondo K, Li M, Ajani J and Janjigian Y: LBA6_PR Nivolumab (nivo) plus chemotherapy (chemo) versus chemo as first-line (1L) treatment for advanced gastric cancer/gastroesophageal junction cancer (GC/GEJC)/esophageal adenocarcinoma (EAC): First results of the CheckMate 649 study. Annals of Oncology 31: S1191, 2020. DOI: 10.1016/j.annonc.2020.08.2296

7 Matsumoto R, Arigami T, Matsushita D, Okubo K, Tanaka T, Yanagita S, Sasaki K, Noda M, Kita Y, Mori S, Kurahara H and Ohtsuka T: Conversion surgery for stage IV gastric cancer with a complete pathological response to nivolumab: a case report. World J Surg Oncol 18(1): 179, 2020. PMID: 32693806. DOI: 10.1186/s12957-020-01954-0

8 Toyota S, Naito H, Motoyoshi S, Nakanishi R, Oki E, Orita H and Korenaga D: Extended total gastrectomy after nivolumab for unresectable multivisceral invasive gastric cancer. Surg Case Rep 6(1): 298, 2020. PMID: 33237443. DOI: 10.1186/s40792020-01040-3

9 Toyota S, Orita H, Fukuyama Y, Motoyoshi S, Kawanami S, Maeda S, Kuramitsu E, Ichimanda M, Nagamatsu S, Nagata S, Kai S, Korenaga D and Mori M: Successful conversion surgery following chylous ascites after nivolumab for advanced gastric cancer. In Vivo 34(2): 583-585, 2020. PMID: 32111756. DOI: 10.21873 /invivo. 11810 
10 Kim ST, Cristescu R, Bass AJ, Kim KM, Odegaard JI, Kim K, Liu XQ, Sher X, Jung H, Lee M, Lee S, Park SH, Park JO, Park YS, Lim HY, Lee H, Choi M, Talasaz A, Kang PS, Cheng J, Loboda A, Lee J and Kang WK: Comprehensive molecular characterization of clinical responses to PD-1 inhibition in metastatic gastric cancer. Nat Med 24(9): 1449-1458, 2018. PMID: 30013197. DOI: 10.1038/s41591-018-0101-Z

11 Chen LT, Satoh T, Ryu MH, Chao Y, Kato K, Chung HC, Chen JS, Muro K, Kang WK, Yeh KH, Yoshikawa T, Oh SC, Bai LY, Tamura T, Lee KW, Hamamoto Y, Kim JG, Chin K, Oh DY, Minashi K, Cho JY, Tsuda M, Sameshima H, Kang YK and Boku $\mathrm{N}$ : A phase 3 study of nivolumab in previously treated advanced gastric or gastroesophageal junction cancer (ATTRACTION-2): 2-year update data. Gastric Cancer 23(3): 510-519, 2020. PMID: 31863227. DOI: 10.1007/s10120-019-01034-7

12 Kim J, Kim B, Kang SY, Heo YJ, Park SH, Kim ST, Kang WK, Lee $\mathrm{J}$ and Kim KM: Tumor mutational burden determined by panel sequencing predicts survival after immunotherapy in patients with advanced gastric cancer. Front Oncol 10: 314, 2020. PMID: 32232003 . DOI: 10.3389/fonc. 2020.00314
13 Kinoshita J, Fushida S, Tsukada T, Oyama K, Okamoto K, Makino I, Nakamura K, Miyashita T, Tajima H, Takamura H, Ninomiya I and Ohta T: Efficacy of conversion gastrectomy following docetaxel, cisplatin, and S-1 therapy in potentially resectable stage IV gastric cancer. Eur J Surg Oncol 41(10): 1354-1360, 2015. PMID: 26028256. DOI: 10.1016/j.ejso.2015.04.021
Received May 10, 2021

Revised May 25, 2021

Accepted May 27, 2021 